Yang, X. and Chen, Q. 2001. “A coupled airflow and source/sink model for simulating indoor VOC exposures” Indoor Air, 11(4), 257-269.

\title{
A Coupled Airflow and Source/Sink Model for Simulating Indoor VOC Exposures
}

\author{
X. Yang ${ }^{1}$ and Q. Chen ${ }^{2}$
}

1 Department of Civil, Architectural, and Environmental Engineering, University of Miami, Coral Gables, FL 33124-0630, USA, Tel: +1 305284 3456, Fax: +1 305 284 3492, e-mail: xudongy@miami.edu

2 Building Technology Program, Massachusetts Institute of Technology, 77 Massachusetts Avenue, Cambridge, MA 02139, USA

\begin{abstract}
In this paper, a numerical model is presented to study the indoor air quality (IAQ) in a room with different emission sources, sinks, and ventilation methods. A computer program, ACCESS-IAQ, is developed to simulate the airflow pattern, the time history of the contaminant concentrations in the occupied zone, and the inhalation exposures. The program developed may be useful for IAQ professional to design healthy and comfortable indoor environments.

A numerical study has been carried out to predict the effectiveness of a displacement ventilation and a mixing ventilation on volatile organic compound (VOC) removal in a model office. Results from the numerical predictions show that when a "wet" emission source (a freshly painted wood stain) is distributed uniformly across the floor area with sinks (gypsum board) from the four vertical walls, displacement ventilation has consistently lower exposure at the breathing level of the occupant in the room. Such an effect is mainly due to the higher ventilation efficiency of displacement ventilation compared to the mixing ventilation. The simulation results also show that the walls adsorb significant amounts of VOCs during the first hour and act as secondary sources afterwards.
\end{abstract}

Key words VOC; Indoor air quality; Emissions; Sorption; Ventilation; Modeling.

\section{Practical Implications}

Traditionally, building ventilation systems are designed to maintain thermal comfort while controlling carbon dioxide concentrations and odors. Effective removal of indoor-generated contaminants, such as the volatile organic compounds (VOCs) from building materials, is generally not a design criterion in office buildings. This paper presents a computational fluid dynamics (CFD) model for estimating VOC exposures in a room with different emission sources, sinks, and ventilation methods. A first application of the model indicates that displacement ventilation may also improve IAQ when a passive contaminant source (a source that is not associated with heat release) is distributed uniformly across the floor area with sinks from the vertical walls. 


\section{Introduction}

Indoor environment is important to workers' health and welfare. In the developed world, more than half of the workforce is employed indoors and up to $90 \%$ of a typical worker's time is spent indoors (Spengler, 1991). Several recent studies by the U.S. Environmental Protection Agency (EPA) have identified indoor air pollution as one of the top environmental risks to the Nation's health (U.S. EPA, 1987; 1995). The high risk from exposure to indoor air pollution reflects the elevated concentrations of indoor contaminants, the large number of people exposed to indoor air pollution, and the amount of time spent indoors (U.S. EPA, 1995).

Volatile organic compounds (VOCs) constitute an important class of indoor-air contaminants. Evidence from a variety of non-industrial building investigations and systematic studies found that $60 \%$ of the VOCs indoors come from building materials and furnishings (De Bellie et al. 1995). Various VOCs have been associated with certain symptoms of sick building syndrome and multiple chemical sensitivity, and other health effects. In addition, excessive exposure to VOCs in work environment can lower worker productivity and cause materials and equipment damage.

With the growing awareness of the problems associated with indoor VOC exposures, there is now a strong impetus to design and construct buildings with a healthy and comfortable indoor environment. Source reduction, such as selection of low VOC emitting building materials and cleaning solvents used in the building is a common method of reducing VOC emissions indoors. However, this approach may not always be practical, and it requires constant vigilance against new materials and new chemicals from being brought into the building.

Ventilation, with appropriate air-handling processes, is used to create an indoor environment with acceptable air temperature, humidity, air velocity and to remove indoor contaminants for better indoor air quality (IAQ). Traditionally, building ventilation systems are designed to maintain thermal comfort while controlling carbon dioxide concentrations and odors (ASHRAE, 1989). Effective removal of indoor-generated contaminants is generally not a design criterion in non-industrial buildings. The ventilation systems in those buildings may not remove the VOCs properly.

In actual buildings, the pollutant generation, sorption, and distribution may be significantly influenced by the ventilation method used and building configurations. Different ventilation systems create different airflow patterns and temperature, humidity, and turbulence profiles. Such a difference can affect the fate and pathways of VOCs indoors. Inadequate ventilation can increase indoor pollutant levels by not effectively distributing the supply air to dilute emissions from indoor sources and by not carrying indoor air pollutants out of the building. Conversely, appropriate design of ventilation systems adds new dimensions for better IAQ and for energy saving at the same time.

Two main research methods are available for the combined problem of indoor sources, sinks, and their interaction with airflow and thermal conditions: experimental investigation and computer simulation. In principle, direct measurements give the most realistic information concerning IAQ. However, experimental method requires full-scale, well-controlled facilities 
(e.g., a test house). Such facilities with necessary equipment for measuring air velocity, temperature, relative humidity, and contaminant concentrations would cost over a half million dollars. Furthermore, direct measurements of the VOC distributions in a full-scale room are time consuming and technically difficult.

Due to the limitations of the experimental approach, computer models (IAQ models) have been developed and increasingly used for predicting indoor air pollutant concentrations. For example, Molhave (1982) used the VOC emission rates of 42 indoor materials, measured in a test chamber, and calculated the steady-state indoor air concentrations of pollutants originating from these materials. Neretnieks et al. (1993) developed a compartment model to describe the emission, sorption, and re-emission of VOCs from/to various building materials and furniture in a room. The compartment model assumes that the system to be modeled is represented by a number of compartments in contact with each other. Each object (e.g., a wall) in the system consists of one or more compartments, and the concentration in each compartment is assumed to be uniform.

Based on the results of indoor contaminant concentrations, the models for exposure assessment of an individual or a population are also available. For example, Hayes (1989) developed a single compartment model for analysis of a population exposed to a wide range of indoor air pollutants. Sparks (1991) developed another model, EXPOSURE, for analysis of individual exposure. The model can be used to provide guidance to individuals on reducing their exposure to pollutants from indoor sources. It can also provide individual guidance in the effectiveness of IAQ control options of specific situations.

The type of mixing between the pollutants and the room air must be specified in an IAQ model. Because mixing is complex, many existing models use simplifying assumptions, such as the well-mixing assumption. While this assumption may be acceptable in some circumstances, it may not be generalized in buildings. Concentrations can vary spatially within a room due to the distributions of contaminant sources, sinks, the placement of fans, location and discharge characteristics of supply or exhaust openings, internal barrier to air flow, and thermal gradients in the room, etc. Many researchers have measured or calculated the non-uniform contaminant distributions in a room (e.g., Haghighat et al., 1994; Brohus, 1997). Further, mixing may also affect the emission or sorption rates of building materials. This problem will be more pronounced for "wet" sources because the local VOC concentration in the air affects the mass transfer rate at the material-air interface.

A recent review by Ellacott and Reed (1999) identified five principal factors controlling the generation and ultimate fate of an emission in a room with restricted flow: sources, sorption/desorption, mixing volume, air exchange, and removal. In order to account for these factors especially the possible non-uniform VOC distributions in buildings, models based on computational fluid dynamics (CFD) techniques have also been developed. The CFD-based IAQ models solve a set of conservation equations describing the flow, energy, and contaminants in the system. Due to the increase in performance and affordability of high-speed computers, the numerical solution of these conservation equations provides a practical alternative for analyzing IAQ in buildings. For example, Haghighat et al. (1994) numerically studied the IAQ in a newly painted partitioned office by using a CFD code with the k- $\varepsilon$ turbulence model (Launder and 
Spalding, 1974). The emission source in the model was simulated by using the VB (Vapor pressure and Boundary layer) model (Guo and Tichenor, 1992). Yang et al. (2000a) used a more comprehensive emission source model to simulate the impact of airflow on VOC emission rates from a freshly painted wood stain. No sinks were considered in the above studies.

This paper attempts to expand the existing work by developing a CFD-based model for general IAQ studies. The new model integrates the effects of airflow and the mass transfer processes associated with the VOC emission sources and sinks to yield the detailed distributions of airflow, temperature, and contaminant in buildings. Such knowledge is needed by engineers and architects for selecting appropriate ventilation systems and control strategies to minimize indoor contaminant exposures. Use of the model is demonstrated by applying it to study IAQ in a room with two different ventilation methods: a displacement ventilation and a mixing ventilation.

\section{Model for IAQ Studies}

An IAQ model that integrates the major influencing factors is a combination of several models including a room air model and emission source and sink models. An exposure model is also needed to predict individual exposures based on the temperal and spatial distributions of pollutants. The following describes these models with emphasis on VOC generation and sorption from/to building materials.

\section{The room air model}

Room air distributions are important to IAQ because they not only determine the indoor contaminant distributions, but may also affect the emission and sorption rates of materials. Hence, an accurate prediction of air distributions is necessary. On the other hand, previous studies have shown that simulating room air and the air phase VOC transport usually takes major computing time for an emission study (Yang et al., 2000a). This is also true for IAQ simulations because an IAQ study in buildings is usually a 3-D transient problem. Therefore, the room air model must also be computationally efficient.

Most indoor airflows involve all three types of convection regions: forced, natural, and mixed (a combined forced and natural). In a typical air-conditioned room with equipment (computers, etc.) or exterior hot/cold walls or windows, the airflow is mixed convection. In order to simulate room airflow that is highly turbulent, a suitable turbulence model is needed so that the flow can be simulated with currently available computer capacities.

Many turbulence models are available for different types of flow. The "standard" k- $\varepsilon$ model (Launder and Spalding, 1974) is widely used but sometimes provides poor results for indoor airflow and heat transfer. To consider the low-velocity and buoyant characteristics of room airflow, many researchers have employed low-Reynolds-number (LRN) turbulence models that consider the damping effects of the wall (Blay et. al., 1992; Chen, 1995; Murakami et al., 1996). Some researchers have used more advanced turbulence models, such as the Reynolds-stress models (RSM) (Peeters and Henkes, 1992; Chen, 1996) for indoor airflow simulation. It is well known that LRN turbulence models demand fine grids near walls and raise computing costs significantly. A non-steady, three-dimensional airflow calculation by a LRN model requires a computing capacity close to that of the Large Eddy Simulation. Using more advanced models such as RSMs in a similar case requires very high computing capacity, since in addition to 
considering LRN effects, RSMs must solve many differential equations simultaneously. Further, Chen (1996) pointed out that RSMs do not perform much better than the standard k- $\varepsilon$ model but they have a much higher computing cost.

A new two-layer model that attempts to solve the conflict between the simulation accuracy and computing cost has been recently developed (Xu and Chen, 2000a; 2000b). The model uses a one-equation $(\mathrm{k})$ model for the near wall region and the "standard" $\mathrm{k}-\varepsilon$ model in the outer region. The near-wall models have been developed with the aid of the data of natural and forced convection flows by Direct Numerical Simulation. Studies by $\mathrm{Xu}$ and Chen showed that the twolayer model performed better than many $k-\varepsilon$ models in predicting airflows and heat transfer for natural, forced, and mixed convection cases. The computing cost is significantly lower than that of the LRN k- $\varepsilon$ models and is only slightly higher than that of the "standard" $k-\varepsilon$ model. Thus, the two-layer model is used in our IAQ study.

\section{The emission source models}

The behavior of sources plays a key role in determining the indoor concentration as a function of time. Sparks (1991) divided sources into three major categories:

(1) Long term steady state sources such as moth cakes

(2) On/off sources such as heaters

(3) Decaying sources such as many "wet” and dry materials

A lot of efforts have been made in modeling VOC emissions from the last class of sources. Ellacott and Reed (1999) reviewed many types of models developed and broadly classified those models as non-physical (statistical) or physical (deterministic). Non-physical models derive a mathematical equation based solely on the observation and statistical analysis of emission data obtained from environmental chamber testing. These models are usually not able to provide insight into the physical emission mechanisms and do not allow scaling of the results from one condition (e.g., in a small-scale chamber) to another (e.g., in a building). Thus, they are not considered in the IAQ study.

The physical models are developed by assuming that VOC emissions from building materials are governed by well-established mass transfer principles and hence are predictable using mechanistic mathematical models. From a mass transfer point of view, two main mechanisms contribute to material emissions: VOC diffusion in a material as a result of a concentration or temperature gradient, and interfacial mass transfer due to the interaction of the material surface with the adjacent air. Unlike the non-physical models, mass transfer models allow separation of internal and external factors. This allows scaling the model parameters developed from chamber experiments to buildings.

A brief review of the available physical models as applied to both dry and "wet" sources is given below.

Dry materials Most existing models for dry materials assume that emissions are exclusively dominated by internal diffusion. For a porous material, two kinds of diffusion are key to this process: molecular diffusion and Knudsen diffusion. When the capillary size is large compared 
to the mean molecular free path of VOC, $\lambda$, molecular diffusion prevails. On the other hand, when the capillary size is smaller than $\lambda$, the Knudsen diffusion predominates. Because diffusion process is complex, simplified approaches are usually employed to characterize the process. One of the simple approaches is the use of continuum model. The continuum model treats the material as a homogeneous medium that can be characterized by an effective diffusion coefficient, $\mathrm{D}_{\text {eff. Introduction of }} \mathrm{D}_{\text {eff }}$ allows the use of Fick's law to predict the mass transfer within a source.

Several authors have used Fick's law to simulate dry material emissions. For example, Dunn (1987) calculated diffusion-controlled compound emissions from a semi-infinite source. Little et al. (1994) simulated the VOC emissions from new carpets using the assumption that the VOCs originate predominately in a uniform slab of polymer backing material. These models neglected several minor factors, such as the mass transfer resistance through the air phase boundary layer. A numerical model that considers both internal diffusion and interfacial mass transfer was also available (Yang et al., 2000b).

Different mass transfer models may be selected to accommodate different IAQ modeling requirements. For materials with small diffusivity to VOCs (e.g., $10^{-12} \mathrm{~m}^{2} / \mathrm{s}$ ), a sensitivity study by Little et al. (1994) and Yang et al. (2000b) concluded that the partition coefficient, material age, and air-phase mass transfer coefficient affect only the short-term emissions. They have virtually no impact to long-term emissions. Thus, for estimating the long-term IAQ effect simplified models can be used to derive the time-dependent emission rates based solely on the diffusion coefficient and initial VOC concentration in the materials. Otherwise a complex model (e.g., Yang et al., 2000b) may be necessary for detailed, short-term studies.

The key to the successful use of mass transfer models relies on the availability of material property data: the diffusion coefficient, $\mathrm{D}_{\mathrm{s}}$, and the partition coefficient, $\mathrm{K}$. Direct measurements of $\mathrm{D}_{\mathrm{s}}$ and $\mathrm{K}$ for several homogeneous, non-porous materials have been conducted by Bodalal et al. (1999), Kirchner et al. (1999), and Zhao et al., (1999), among others. The above authors have published experimental data of $\mathrm{D}_{\mathrm{s}}$ and $\mathrm{K}$ for materials including vinyl flooring, carpet backing, plywood, wall paper, carpet with polypropene styrene-butadiene rubber backing, etc. Useful correlations of $\mathrm{D}_{\mathrm{s}}$ and $\mathrm{K}$ with the compound's vapor pressure and/or molecular weight have also been proposed.

"Wet" coating materials Interior architectural coatings such as wood stains, vanishes, and paints are widely used in buildings. Most of these "wet" coatings contain petroleum-based solvents and thus emit a wide variety of VOCs. Using environmental chambers, previous studies have indicated that the emission process of "wet" materials appears to have three phases (Chang and Guo, 1992; Zhang et al, 1999). The first phase represents the period shortly after the material is applied but is still relatively wet. The VOC emissions in this phase are characterized by high emission rates but fast decay. It appears that emissions are related to evaporation at the surface of the material. In the second phase, the material dries as emissions transition from an evaporation-dominant phase to an internal-diffusion controlled phase. In the third phase the material becomes relatively dry. In this phase the VOC off-gassing rate decreases and so does the decay rate. The dominant emission mechanism in this phase is believed to be the internal diffusion of VOCs through the substrate. Previous studies have also found that the emissions of 
"wet" materials are likely to depend on environmental conditions (temperature, air velocity, turbulence, humidity, VOC concentration in air) and also physical properties of the material and the substrate (e.g., Zhang et al., 1996; Chang et al., 1997; Haghighat and De Bellis, 1998; Wolkoff, 1998).

Many emission source models for "wet" materials are mainly focused on the evaporation dominant stage. Sparks et al. (1996) developed a correlation of the gas phase mass transfer coefficient with the flow Reynolds number and the VOC Schmidt number. The Vapor pressure and Boundary layer (VB) model (Guo and Tichenor, 1992) considers emission as a pure evaporation process and neglects internal diffusion. It has been found that such a model may not work well for the entire emission process, especially when the material becomes relatively dry (Sparks et al., 1999). Recently, researchers have proposed semi-empirical models (e.g., Guo et al., 1996; Sparks et al., 1999) to examine the entire process (from "wet" to dry). However, the use of empirical factors limits the general applicability of these models.

A CFD model that covers both the evaporation- and internal diffusion-controlled phases of emissions has been recently developed (Yang et al., 2000c). The model assumes that emissions from a "wet" material (e.g., a wood stain) applied on a porous substrate (e.g., an oak board) includes the diffusion of VOCs through the material film imbedded in the substrate, the substrate layer which is initially free from the coating compounds, the material-air interface, and the airphase boundary layer (Figure 1). The governing equations for each region, starting from the substrate, are:

- Substrate: one-dimensional transient diffusion equation.

- Material film: three-dimensional transient diffusion equation for free and bound VOCs (vapor flow is neglected).

- Interface: partition coefficient to relate the VOC concentrations between the material side and the air side of the interface.

- Boundary layer and above: three-dimensional conservation equations for mass, momentum, energy, and VOC species.

Yang et al. (2000a; 2000c) demonstrated that the above model can simulate "wet" material emissions in a small-scale chamber as well as a full-scale room, considering the effects of temperature, air velocity, and turbulence on emissions. The model is used in the IAQ study.

\section{The material sorption model}

Indoor sinks can also play an important role in determining indoor pollutant concentrations. The significant impact of sinks is that they become sources when the original pollutant source is removed or when the strength of the original source drops below a certain value. Guo (1993) and Zhang et al. (2000) reviewed the existing VOC sorption models and classified them into statistical models and theoretical models. Statistical models view sorption as a surface phenomenon. A two-way process, adsorption and desorption, is assumed to occur simultaneously at the material surface. Common statistical models include the linear Langmuir model (Tichenor et al., 1991) and the two-sink model (Colombo et al., 1993; De Bortoli et al, 1996). As an example, the linear Langmuir model uses the following differential equation to describe the nonequilibrium process at a material surface (Figure 2a): 


$$
\mathrm{dM} / \mathrm{dt}=\mathrm{k}_{\mathrm{a}} \mathrm{C}-\mathrm{k}_{\mathrm{d}} \mathrm{M}
$$

Where M is the VOC mass adsorbed per unit surface area $\left(\mathrm{mg} / \mathrm{m}^{2}\right)$, C is the VOC concentration in the bulk air $\left(\mathrm{mg} / \mathrm{m}^{3}\right), \mathrm{k}_{\mathrm{a}}$ is the adsorption coefficient $(\mathrm{m} / \mathrm{h})$ and $\mathrm{k}_{\mathrm{d}}$ is the desorption coefficient $(1 / h)$.

A nonlinear regression method has to be used to determine the $k_{a}$ and $k_{d}$ in Eq. (1). This is done by adjusting the two unknown parameters until the model predictions agree with the experimental data. It has been found that given different initial estimations of initial parameters, the fitted parameters may not be unique and the results may differ as much as a factor of 100 (De Bellis et al., 1996; Zhang et al., 2000). Thus, the results may not always be reliable.

In contrast, theoretical models assume that VOC diffusion occurs in both the material and the bulk air while an equilibrium is always established at the interface (Figure 2b). In many simple cases, the equilibrium can be assumed to follow the linear isotherm shown in Eq. (2):

$$
\mathrm{C}_{\mathrm{m}}=\mathrm{K}_{\mathrm{ma}} \mathrm{C}_{\mathrm{a}}
$$

Where $\mathrm{K}_{\mathrm{ma}}$ is the material-air partition coefficient (dimensionless), $\mathrm{C}_{\mathrm{m}}$ and $\mathrm{C}_{\mathrm{a}}$ are the interfacial concentrations $\left(\mathrm{mg} / \mathrm{m}^{3}\right)$ in the material phase and air phase, respectively. Theoretical models can then be developed by combining Eq. (2) with the in-material Fick's law and a gas-phase model. The model parameters are the partition coefficient and the diffusion coefficient, same as those used in the material emission models. Examples of theoretical models include the boundary layer diffusion control model (Axley, 1991), the diffusion-controlled sink model (Little and Hodgson, 1996), and the numerical model (Yang et al., 2000d). These models treat the similar governing equations in different ways and yield different solutions.

In the forthcoming IAQ study, the numerical model will be used for simulating the sink effect. The significance of the this model is that it provides a relatively simple relationship for the prediction of sorption based solely on the physical properties (diffusion coefficient and partition coefficient) of the material. It can be used as a "wall function" in combination with more complex gas-phase models that account for non-uniform mixing to predict sorption process. Studies show that the model can simulate the general trend of the sorption curve of a gypsum board against three different compounds (ethylbenzene, benzaldehyde, dodecane) (Yang et al. 2000d).

\section{The exposure model}

Because the most common route for exposure to indoor air pollutants is by inhalation, it is convenient to use inhalation exposure given by Sparks (1991):

$$
\mathrm{E}_{\mathrm{i}}(\tau)=\mathrm{C}(\tau) \mathrm{bv}
$$


where $E_{i}(\tau)$ is the inhalation exposure at time $\tau(\mathrm{mg} / \mathrm{h}), \mathrm{C}(\tau)$ is the pollutant concentration at time $\tau\left(\mathrm{mg} / \mathrm{m}^{3}\right), \mathrm{b}$ is the breathing rate (breath/hour), and $\mathrm{v}$ is the volume per breath $\left(\mathrm{m}^{3} / \mathrm{breath}\right.$ ). When the room air is not well-mixed, both $\mathrm{C}(\tau)$ and $\mathrm{E}_{\mathrm{i}}(\tau)$ vary with the location in the room.

The exposure defined by Eq. (3) is instantaneous, i.e., the exposure at any instant time, $\tau$. The cumulative inhalation exposure (doze, in $\mathrm{mg}$ ) between time $\tau_{1}$ and $\tau_{2}$ is:

$$
\mathrm{E}_{\mathrm{ic}}=\int_{\tau 1}^{\tau 2} \mathrm{C}(\tau) \mathrm{bvd} \tau
$$

In order to determine the time a person is exposed to the concentration, the individual's activity pattern is also required. An activity pattern is defined by the time a person enters and leaves the building (Sparks, 1991), while remaining at a fixed location in the room.

\section{Numerical Method and the Computer Program ACCESS-IAQ}

The IAQ model described above is suitable for the detailed study of material emission, sorption, and their impact on IAQ. Numerical solution of the governing equations in general requires solving the room air and VOC source, sink, and transport simultaneously. However, by assuming that VOCs have a negligible impact on airflow and heat transfer, the process can be separated into two parts. First, we simulate the room air and obtain the steady-state distributions of air temperature, velocity, and turbulent intensity using a CFD program. The flow and temperature results are then incorporated into the VOC mass-transfer equations for simulating emissions, sorption, and IAQ.

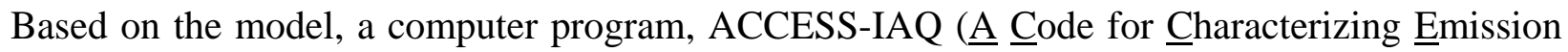
Sources, Sinks, and Indoor Air Quality), has been developed. The program can be used for the following purposes:

(1) Study the VOC emissions from different types of building materials ("wet” or dry materials). The model inputs are the flow and thermal boundary conditions and material properties (diffusion coefficient and partition coefficient).

(2) Study the VOC sorption by building materials using the numerical model described above.

(3) Study the combined problem of indoor airflow, thermal comfort, IAQ, and exposures. The computer code allows the user to specify multiple sources/sinks and different boundary conditions for different ventilation methods.

\section{Model Applications}

Using the computer program ACCESS-IAQ, this section presents results of a numerical simulation of VOC removal in a full-scale room with sources and sinks from the interior building materials. The effectiveness of a displacement ventilation and a mixing ventilation on VOC removal is evaluated by comparing the VOC concentrations and personal exposure at the breathing level in the room. The effects of sinks on IAQ will also be discussed. 


\section{Case description}

The case study is concerned with the interaction among indoor VOC sources, sinks, and ventilation systems and their impact on indoor contaminant distributions and personal exposures. A $5.16 \mathrm{~m} \times 3.65 \mathrm{~m} \times 2.44 \mathrm{~m}$ model room, taken after an experimental set-up (Yuan et al., 1999), is assumed to be occupied by two persons and equipped with two tables, two computers, two file cabinets and six overhead lights (Figure 3). A $3.65 \mathrm{~m} \times 1.04 \mathrm{~m}$ window is mounted on the wall connecting the office to another room where the temperature was controlled to simulate outdoor conditions. All other walls are insulated to minimize the heat gain/loss.

Each occupant in the test room is simulated by a box, $0.4 \mathrm{~m}$ long, $0.35 \mathrm{~m}$ wide, and $1.1 \mathrm{~m}$ high, heated by three light bulbs. The supply air temperature is controlled at $17.0{ }^{\circ} \mathrm{C}$. Other temperatures of the interior surfaces are measured and given by Chen et al. (1999). The window surface temperature is 27.3 - $28.1{ }^{\circ} \mathrm{C}$ (for summer condition). The surface temperature on the floor is a fixed $23.5{ }^{\circ} \mathrm{C}$. Surface temperatures on the other walls are $23.3-26.6{ }^{\circ} \mathrm{C}$. The internal heat sources and the ventilation rate are listed in Table 1 . The hypothetical VOC sources, sinks, and ventilation methods of the room are give as follows:

Internal VOC source: A freshly painted wood stain with oak substrate. The source represents "wet" materials applied to a realistic substrate. The source is distributed on the open area of the floor (area $17.7 \mathrm{~m}^{2}$ ). A total of $1.33 \mathrm{~kg}$ of wood stain is applied to have a same film thickness as that of the case tested in a small-scale chamber (Yang et al., 2000c). The physical properties of the wood stain are given in Table 2.

VOC sinks: The four vertical walls in the room. Each wall is assumed to be made of unpainted gypsum board. Based on the sorption data measured by An et al. (1999), Yang (1999) estimated a diffusion coefficient of $5.67 \times 10^{-12} \mathrm{~m}^{2} / \mathrm{s}$ and a partition coefficient of 8600 for the gypsum board. The values are used for the material-VOC assembly. The total sink area is $43 \mathrm{~m}^{2}$.

Ventilation methods:

- Displacement ventilation: supply from a displacement diffuser on the rear-wall (opposite to the window) near the floor and exhaust on the ceiling (Figure 4a).

- Mixing ventilation: supply from two four-way diffusers on the ceiling and exhaust from a rear-wall grille near the floor (Figure 4b).

\section{Results and discussion}

Both airflow and temperature may affect material emissions, sorption, and IAQ. However, temperature is not a concern for the cases studied because the temperatures of both the emission source and sinks are close to constant $\left(23.5^{\circ} \mathrm{C}\right)$.

The simulated airflows for the displacement ventilation are given in Figure 5. The results agree well with the measured airflow patterns (using smoke), velocity and velocity fluctuation (using hot sphere anemometers), and temperature (using thermalcouples) (Xu and Chen, 2000b). The velocity vectors at two sections, one at the room center $(\mathrm{y}=1.83 \mathrm{~m})$ and the other across the occupant $1(\mathrm{y}=1.03 \mathrm{~m})$ for the displacement ventilation system are shown in Figure 5 . At the 
room center, cold air from the supply diffuser spreads on the floor level and induces a reverse flow in the layer between $0.5 \mathrm{~m}$ and $1.0 \mathrm{~m}$ above the floor. Figure 5(b) shows the thermal plume generated by the occupant. The plume entrains air from both the floor level and the recirculated area (about $1.0 \mathrm{~m}$ above the floor).

Predicted airflows for the mixing ventilation are shown in Figure 6. The jet flow near the diffusers generates recirculation between the two diffusers. Due to the cold downward flow from the diffusers, the upward plume by the occupant is very weak.

When the two ventilation systems are compared, the major part of the displacement ventilation is a horizontal flow while the mixing has an irregular flow pattern. These different airflow patterns may exert an influence on the emission sources, sinks, contaminant distributions, and thus personal exposure.

Due to the type of source selected, both the emission/sorption rates and VOC concentrations in the room are time-dependent. The history of concentrations at the breathing level for occupant 1 during the first four days after the wood stain is applied is presented in Figure 7. The concentrations first increase rapidly and reach a peak in about 0.5 hour. After that, the concentrations begin to decay. For both ventilation methods, the VOC concentrations drop from the peak values ( $>2000 \mathrm{mg} / \mathrm{m}^{3}$ ) to less than $2 \mathrm{mg} / \mathrm{m}^{3}$ four days after the wood stain is applied. Although not shown, results at occupant 2 and the room average at the breathing level $(z=1.0$ m) follow the same trend.

It is useful now to consider the potential health effects due to the presence of the VOCs in this office. Andersson et al. (1997) reviewed numerous human experimental investigations in which subjects were exposed in exposure chambers to VOC mixtures or individual VOCs. The experimental investigations found that odors are significant at TVOC concentrations of 3 to 25 $\mathrm{mg} / \mathrm{m}^{3}$, and irritation to eyes, nose, and mouth at TVOC concentrations of 5 to $25 \mathrm{mg} / \mathrm{m}^{3}$. Using $3 \mathrm{mg} / \mathrm{m}^{3}$ as the odor threshold and $5 \mathrm{mg} / \mathrm{m}^{3}$ as the irritation threshold, TVOC concentrations during the first day are about 2 to 400 times higher than the irritation threshold. A significant health effect will result if a person stays in the room during this period. However, due to the decay of the emission source, VOC concentrations will finally decay to the values below the irritation or odor thresholds. The results show that about 60 hours are required for both ventilation systems to reduce the average TVOC concentrations in the breathing zone below the odor threshold $\left(3 \mathrm{mg} / \mathrm{m}^{3}\right)$.

Figure 8 compares the predicted daily accumulated exposure (dose) for occupant 1 , assuming both occupants stay 10 hours per day $(9 \mathrm{am}-7 \mathrm{pm})$ starting from the second day, and at a fixed location within the room. The results show that displacement ventilation generates considerably lower exposure than the mixing ventilation. The difference could be due to (a) the difference in terms of emission source/sink rates, and (b) the difference in terms of ventilation efficiency. Effects of these factors are now examined.

Figure 9 gives the history of the VOC emission rates from the source (wood stain). The results show that the mixing ventilation generates higher initial emission rates than the displacement ventilation does. The order is reversed after about 0.5 hour for about three days. After that the 
two emission curves tend to be identical. The results reflect that the mixing ventilation generates a higher gas-phase mass transfer coefficient on the floor than the displacement ventilation does. The gas-phase mass transfer coefficient is determined by combined factors of air velocity, turbulence, and flow direction near the surface of the emission source exerted by the ventilation systems. The results also indicate that the difference in exposure on the fourth day is not due to the emission source, since there are no noticeable differences between the two ventilation systems after three days.

Figure 10 compares the simulated sorption rates due to the four walls in the model room. A negative value of the sorption rate means that there is uptake of VOCs by the sinks, whereas a positive one means release of VOCs from the sinks. The results indicate that the walls adsorb significant amounts of VOCs during the first hour when the VOC concentrations in the room are high. After that, the walls begin to release VOCs and act as a secondary source. Figure 11 further demonstrates the relative strength of the sink by showing the percentage of the desorption rate of the sinks to the emission rate from the source at the same time. For both ventilation methods, the re-emission from the sinks after three days accounts to less than $10 \%$ of the emissions from the original source. Given an almost identical source emission rates and a maximum $30 \%$ difference in re-emission rates between the two ventilation methods (Figure 10c), the total VOC generation rates (emission and re-emission) between the two ventilation methods should differ by no more than $3 \%$.

The above results indicate that for the two cases compared, higher ventilation efficiency of displacement ventilation is likely the major factor to the lower exposures in the room. This has been supported by simulation results using a constant area source on the floor without a sink (Yang, 1999). Previous experimental measurements have found that displacement ventilation improves the IAQ when the contaminant sources are non-passive (i.e., sources are associated with a heat source) (Brohus and Nielsen, 1996; Yuan et al., 1999). Results from the above study show that displacement ventilation may also improve IAQ for passive contaminant sources. However, further investigations are needed before a general conclusion can be drawn.

It should be pointed out that the purpose of the above case study is to demonstrate the method of an integrated study of material emissions, sorption, and IAQ. The model room considered may be too ideal compared to a real room. To acquire more reliable results from the simulations, work is needed to identify and simplify the emission sources and sinks included in a building and the associated material properties (e.g., diffusion coefficient and partition coefficient). Further experimental verification is also needed to validate the simulation results.

\section{Conclusions}

This paper presents an indoor air quality (IAQ) model for the combined problem of material emissions, sorption, and IAQ in buildings. A computer program, ACCESS-IAQ, has been developed and applied for studying IAQ in a small office with a displacement ventilation or a mixing ventilation method. The following conclusions can be drawn based on the results from the numerical simulations:

(1) When a "wet” emission source (a freshly painted wood stain) is distributed uniformly across the floor area with sinks (gypsum board) from the four vertical walls, displacement ventilation 
has consistently lower exposure at the breathing level of the occupant in the room. Such effect is caused by mixed factors, including different emission/sorption rates from the source/sinks and the ventilation efficiency of different ventilation methods. For the two cases compared, higher ventilation efficiency of displacement ventilation is likely the major factor to the lower exposures in the room.

(2) The gypsum walls can adsorb significant amounts of VOCs during the first hour and act as secondary sources afterwards. As a result, the sinks can lower the peak concentration and elevate the concentrations after the peak time.

\section{Acknowledgements}

This investigation is supported by the US National Science Foundation Grant CMS-9623864. The authors would also like to thank three anonymous reviewers for their careful review of the manuscript and their helpful comments.

\section{References}

An, Y., Zhang, J.S. and Shaw, C.Y. (1999) "Measurements of VOC adsorption/desorption characteristics of typical interior building material surfaces", International Journal of HVAC\&R Research, 5(4), 297-316.

Andersson, K., Bakke, J.V., Bjorseth, O., Bornehag, C.-G., Hongslo, J.K., Kjellman, M., Kjaergaard, S., Levy, F., Molhave, L., Skerfving, S. and Sundell, J. (1997) "TVOC and health in non-industrial indoor environments”, Indoor Air, 7, 78-91.

ASHRAE (1989) ASHRAE Standard 62: Ventilation for Acceptable Indoor Air Quality, Atlanta, GA, American Society of Heating, Refrigerating, and Air-conditioning Engineers.

Axley, J.W. (1991) “Adsorption modeling for building contaminant dispersal analysis”, Indoor Air, 1, 147-171.

Blay, D., Mergui, S. and Niculae, C. (1992) "Confined turbulent mixed convection in the presence of a horizontal buoyant wall jet", Fundamentals of Mixed Convection, HTD 213, 65-72.

Bodalal, A., Zhang, J.S. and Plett, E.G. (1999) "Method for measuring internal diffusion and equilibrium partition coefficients of volatile organic compounds for building materials", Building and Environment, 35(2), 101-110.

Brohus, H. (1997) Personal Exposure to Contaminant Sources in Ventilated Rooms, Ph.D. Thesis, Department of Building Technology and Structural Engineering, Aalborg University, Denmark.

Brohus, H. and Nielsen, P.V. (1996) "Personal exposure in displacement ventilated rooms", Indoor Air, 6, 157-167. 
Chang, J.C.S. and Guo, Z. (1992) “Characterization of organic emissions from a wood finishing product - wood stain”, Indoor Air, 2, 146-153.

Chang, J.C.S., Tichenor, B.A., Guo, Z. and Kreb, K. (1997) "Substrate effects on VOC emissions from a latex paint”, Indoor Air, 7, 241-247.

Chen, Q. (1995) “Comparison of different k-e models for indoor airflow computations”, Numerical Heat Transfer, Part B, 28, 353-369.

Chen, Q. (1996) "Prediction of room air motion by Reynolds-stress models”, Building and Environment, 31(3), 233-244.

Chen, Q., Glicksman, L., Yuan, X., Hu, S., Hu, Y. and Yang, X. (1999) Performance Evaluation and Development of Design Guidelines for Displacement Ventilation, Final report to ASHRAE TC 5.3 - Room Air Distributions in ASHRAE Research Project - RP - 949, Department of Architecture, Massachusetts Institute of Technology, Cambridge, MA.

Colombo, A., De Bortoli, M. and Knoppel, H. (1993) “Adsorption of selected volatile organic compounds on a carpet, a wall coating, and a gypsum board in a test chamber”, Indoor Air, 3, 276-282.

De Bellie, L., Haghighat, F. and Zhang, Y. (1995) "Review of the effect of environmental parameters on material emissions", In: Proceedings of the $2^{\text {nd }}$ International Conference on Indoor Air Quality, Ventilation, and Energy Conservation in Buildings, Montreal, Canada, 111-119.

De Bortoli, M., Knoppel, H., Columbo, A. and Kefalopoulos, S. (1996) “Attempting to characterize the sink effect in a small stainless steel test chamber”, ASTM STP 1287, American Society for Testing and Materials, 307-320.

Dunn, J.E. (1987) "Models and statistical methods for gaseous emission testing of finite sources in well-mixed chambers”, Atmospheric Environment, 21(2), 425-430.

Ellacott, M.V. and Reed, S. (1999) "Development of robust indoor air quality models for the estimation of volatile organic compound concentrations in buildings”, Indoor Built Environment, 8, 345-360.

Guo, Z. (1993) “On validation of source and sink models: problems and possible solutions”, ASTM STP 1205, American Society for Testing and Materials, 131-144

Guo, Z. and Tichenor, B.A. (1992) "Fundamental mass transfer models applied to evaluating the emissions of vapor-phase organics from interior architectural coatings", In: Proceedings of EPA/AWMA Symposium, Durham, NC. 
Guo, Z., Fortman, R., Marfiak, S., Tichenor, B.A., Sparks, L., Chang, J.C.S. and Mason, M. (1996) "Modeling the VOC emissions from interior latex paint applied to gypsum board", In: Proceedings of Indoor Air’96, Vol. 1, 987-991.

Haghighat, F., Jiang, Z. and Zhang, Y. (1994) "The impact of ventilation rate and partition layout on the VOC emission rate: time-dependent contaminant removal”, Indoor Air, 4, 276-283.

Haghighat, F. and De Bellis, L. (1998) "Material emission rates: literature review, and the impact of indoor air temperature and relative humidity”, Building and Environment, 33(5), 261-277.

Hayes, S.R. (1989) "Estimating the effect of being indoors on total personal exposure to outdoor air pollution”, Journal of Air \& Waster Management Association, 39, 1453.

Kirchner, S., Badey, J.R., Knudsen, H.N., Meininghaus, R., Quenard, D., Saarela, K., Sallee, H. and Saarinen, A. (1999) "Sorption capacities and diffusion coefficients of indoor surface materials exposed to VOCs: proposal of new test procedures", In: Proceedings of Indoor Air'99, Vol. 1, 430-435.

Launder, B.E. and Spalding, D.B. (1974) "The numerical computation of turbulent flows", Computer Methods in Applied Mechanics and Energy, 3, 269-289.

Little, J.C., Hodgson, A.T. and Gadgil, A.J. (1994) "Modeling emissions of volatile organic compounds from new carpets”, Atmospheric Environment, 28(2), 227-234.

Little, J.C. and Hodgson A.T. (1996) "A strategy for characterizing homogeneous, diffusioncontrolled indoor sources and sinks”, ASTM STP 1287, American Society for Testing and Materials, 293-304.

Molhave, L. (1982) "Indoor air pollution due to organic gases and vapours of solvents in building materials”, Environment International, 8, 117-127.

Murakami, S., Kato, S., Chikamoto, T., Laurence, D. and Blay, D. (1996) "New low-Reynolds number k- $\varepsilon$ model including damping effect due to buoyancy in a stratified flow field", International Journal of Heat and Mass Transfer, 39(16), 3493-3496.

Neretnieks, I., Christiansson, J., Romero, L., Dagerholt, L. and Yu, J.W. (1993) "Modeling of emission and re-emission of volatile organic compounds from building materials with indoor air applications”, Indoor Air, 3, 2-11.

Peeters, T.W. and Henkes, R.A.W.M. (1992) "The Reynolds-stress model of turbulence applied to the natural-convection boundary layer along a heated vertical plate", International Journal of Heat and Mass Transfer, 35, 403-420. 
Sparks, L.E. (1991) EXPOSURE Version 2 A Computer Model for Analyzing the Effects of Indoor Air Pollutant Sources on Individual Exposure, EPA Report EPA/600/8-91/013, U.S. Environmental Protection Agency, Washington D.C.

Sparks, L.E., Tichenor, B.A., Chang, J. and Guo, Z. (1996) "Gas-phase mass transfer model for predicting volatile organic compound (VOC) emission rates from indoor pollutant sources", Indoor Air, 6, 31-40.

Sparks, L.E., Guo, Z., Chang, J.C.S and Tichenor, B.A (1999) "Volatile organic compound emissions from latex paint - Part 1 chamber experiments and source model development", Indoor Air, 9, 10-17.

Spengler, J.D. (1991) "Indoor air quality issues in buildings", In: Proceedings of the $10^{\text {th }}$ Annual AIOH Conference, S1-S14.

Tichenor, B.A., Guo, Z., Dunn, J.E., Sparks, L.E. and Mason, M.A. (1991) "The interaction of vapor phase organic compounds with indoor sinks”, Indoor Air, 1, 23-35.

U.S. EPA. (1987) Unfinished Business: A Comparative Assessment of Environmental Problems, EPA Report EPA-230/2-87-025, U.S. Environmental Protection Agency, Washington D.C.

U.S. EPA. (1995) Characterizing Air Emissions form Indoor Sources, EPA Report EPA/600/F95/005, U.S. Environmental Protection Agency, Washington D.C.

Wolkoff, P. (1998) "Impact of air velocity, temperature, humidity, and air on long-term VOC emissions from building products”, Atmospheric Environment, 32 (14/15), 2659-2668.

Xu, W. and Chen, Q. (2000a) "A two-layer model for simulating indoor airflow, part I: model development", Energy and Buildings (in Press).

Xu, W. and Chen, Q. (2000b) "A two-layer model for simulating indoor airflow, part II: applications", Energy and Buildings (in Press).

Yang, X.. (1999) Study of Building Material Emissions and Indoor Air Quality, Ph.D. Thesis, Department of Architecture, Massachusetts Institute of Technology, Cambridge, MA.

Yang, X., Chen, Q., Zeng, J., Zhang, J.S., Nong, G. and Shaw, C.Y. (2000a) "Effects of airflow on VOC emissions from 'wet' coating materials: experimental measurements and numerical simulation”, ASHRAE Transactions (in Press).

Yang, X., Chen, Q., Zhang, J.S., Magee,R. Zeng, J. and Shaw, C.Y. (2000b) "Numerical simulation of VOC emissions from dry materials”, Building and Environment (in Press).

Yang, X., Chen, Q., Zeng, J., Zhang, J.S. and Shaw, C.Y. (2000c) "A mass transfer model for simulating volatile organic compound emissions from 'wet' coating materials applied to absorptive substrates", International Journal of Heat and Mass Transfer (In Press). 
Yang, X., Chen, Q., Zeng, J., Zhang, J.S. and Shaw, C.Y. (2000d) “A mass transfer model for simulating VOC sorption on building materials", Atmospheric Environment (in Press).

Yuan, X., Chen, Q., Glicksman, L.R., Hu, Y. and Yang, X. (1999) "Measurements and computations of room airflow with displacement ventilation", ASHRAE Transactions, 105(1), 340-352.

Zhang, J., Zhang, J.S., Chen, Q. and Yang, X. (2000) "A critical review on VOC sorption models", In: Proceedings of Healthy Buildings 2000, Vol. 4, 187-192, Espoo, Finland.

Zhang, J.S., Shaw, C.Y., Kanabus-Kaminska, J.M., MacDonald, R.A., Magee, R.J., Lusztyk, E. and Weichert, H.J. (1996) "Study of air velocity and turbulence effects on organic compound emissions from building materials/furnishings using a new small test chamber”, ASTM STP 1287, American Society for Testing and Materials, 184-199.

Zhang, J.S., Nong, G., Shaw, C.Y. and Wang, J.M. (1999) "Measurements of volatile organic compound (VOC) emissions from wood stains by using an electronic balance”, ASHRAE Transactions, 105(1), 279-288.

Zhao, D.Y., Cox, S.S. and Little, J.C. (1999) "Source/sink characterization of diffusioncontrolled building materials”, In: Proceedings of Indoor Air’99, Vol. 1, 408-413. 
Figure caption:

Figure 1 Schematic representation of the emission mechanisms of a "wet" material embedded in a porous substrate. (a) = evaporation; (b) = movement of free and bound VOCs; (c) = vapor flow; $(\mathrm{d})$ = diffusion to substrate.

Figure 2 Schematic that shows the ways of considering the sorption process by (a) statistical models, and (b) theoretical models.

Figure 3 Configuration of the model office. $1=$ occupant $1 ; 2=$ occupant $2 ; 3=$ computers; $4=$ tables; 5 = furniture; 6 = window; 7 = lights.

Figure 4 Schematic of the model office with (a) displacement ventilation, and (b) mixing ventilation.

Figure 5 Predicted velocity vectors for the displacement ventilation: (a) room center $(\mathrm{y}=$ $1.83 \mathrm{~m})$, (b) across occupant $1(\mathrm{y}=1.03 \mathrm{~m})$.

Figure 6 Predicted velocity vectors for the mixing ventilation: (a) room center (y=1.83m), (b) across occupant 1 ( $\mathrm{y}=1.03 \mathrm{~m})$.

Figure 7 Predicted VOC concentrations at the breathing level for occupant 1 with the source (freshly painted wood stain) on the floor and sinks (gypsum board) from the vertical walls: (a) 0 - 5 h; (b) 5 - 30 h; (c) $30-96$ h.

Figure 8 Daily cumulative VOC exposures for occupant 1, assuming the occupant stays 9 am - 7 $\mathrm{pm}$ at the fixed location within the room, starting from the second day.

Figure 9 Predicted TVOC emission rates from the source (freshly painted wood stain) under different ventilation systems: (a) $0-5$ h; (b) 5 - 30 h; (c) $30-96$ h.

Figure 10 Predicted VOC sorption rates due to the sinks (unpainted gypsum board) under different ventilation systems: (a) $0-5$ h; (b) 5 - 30 h; (c) $30-96$ h.

Figure 11 Percentage of desorption rate by the sinks compared to the emission rate from the source at the same time. 
Table 1 Specification of the internal heat sources and ventilation rate of the model room.

\begin{tabular}{|c|c|c|c|c|c|c|}
\hline Type & $\begin{array}{l}\text { Area } \\
\left(\mathbf{m}^{2}\right)\end{array}$ & $\begin{array}{l}\text { Person } \\
\text { (number) }\end{array}$ & $\begin{array}{l}\text { Equipment } \\
\qquad\left(\mathrm{W} / \mathrm{m}^{2}\right)\end{array}$ & $\begin{array}{c}\text { Lighting } \\
\left(\mathrm{W} / \mathbf{m}^{2}\right)\end{array}$ & $\begin{array}{c}\text { Total internal } \\
\text { load } \\
\left(\mathrm{W} / \mathbf{m}^{2}\right) \\
\end{array}$ & $\begin{array}{c}\text { Ventilation } \\
\text { rate } \\
(1 / h) \\
\end{array}$ \\
\hline $\begin{array}{l}\text { Small } \\
\text { office }\end{array}$ & 18.8 & 2 & 14.9 & 10.8 & 33.7 & 4 \\
\hline
\end{tabular}

Table 2: Physical properties of wood stain applied to an oak substrate (Yang, 1999)

\begin{tabular}{|l|l|l|}
\hline \multicolumn{1}{|c|}{ Property } & Symbol (unit) & TVOC \\
\hline Liquid density & $\rho_{\mathrm{l}}\left(\mathrm{mg} / \mathrm{m}^{3}\right)$ & $8.18 \times 10^{8}$ \\
\hline Initial VOC concentration in liquid & $\mathrm{C}_{\mathrm{l}, 0}\left(\mathrm{mg} / \mathrm{m}^{3}\right)$ & $6.91 \times 10^{8}$ \\
\hline VOC vapor pressure & $\mathrm{C}_{\mathrm{a}, 0}\left(\mathrm{mg} / \mathrm{m}^{3}\right)$ & $1.71 \times 10^{4}$ \\
\hline Partition coefficient & $\mathrm{K}_{\mathrm{ma}}(-)$ & $4.03 \times 10^{4}$ \\
\hline Liquid expansion factor in substrate & $\alpha(-)$ & 1.33 \\
\hline Initial VOC concentration in film & $\mathrm{C}_{\mathrm{m}, 0}\left(\mathrm{mg} / \mathrm{m}^{3}\right)$ & $5.20 \times 10^{8}$ \\
\hline VOC Schmidt number & $\mathrm{Sc}^{3}(-)$ & 2.6 \\
\hline Initial VOC diffusivity in film & $\mathrm{D}_{\mathrm{m}, 0}\left(\mathrm{~m}^{2} / \mathrm{s}\right)$ & $1 \times 10^{-11}$ \\
\hline VOC diffusivity in substrate & $\mathrm{D}_{\mathrm{s}}\left(\mathrm{m}^{2} / \mathrm{s}\right)$ & $1 \times 10^{-14}$ \\
\hline
\end{tabular}




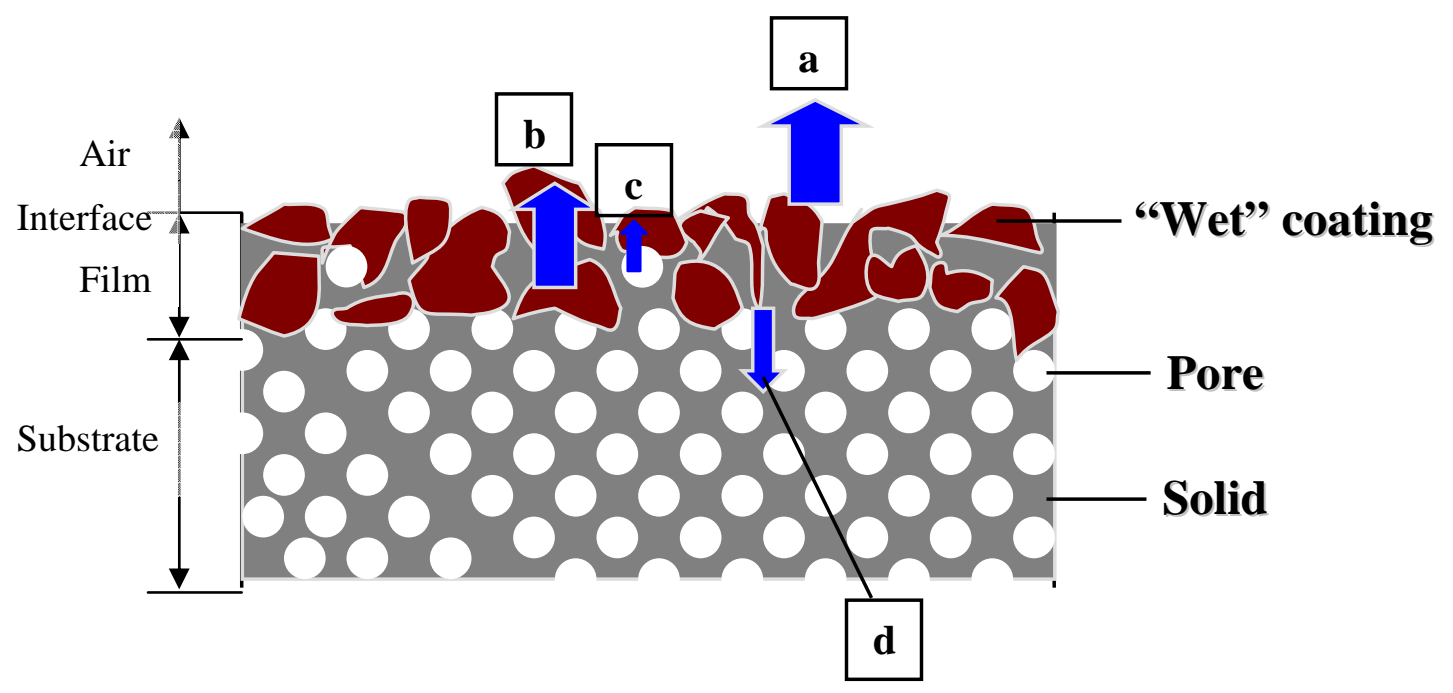

Figure 1 Schematic representation of the emission mechanisms of a "wet" material embedded in a porous substrate. (a) = evaporation; (b) = movement of free and bound VOCs; (c) = vapor flow; (d) = diffusion to substrate. 


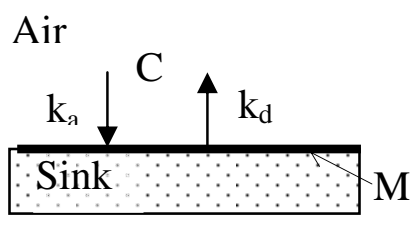

(a)

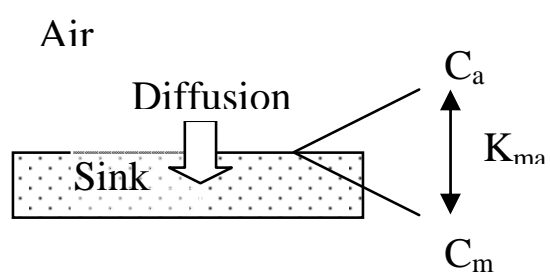

(b)

Figure 2 Schematic that shows the ways of considering the sorption process by (a) statistical models, and (b) theoretical models. 


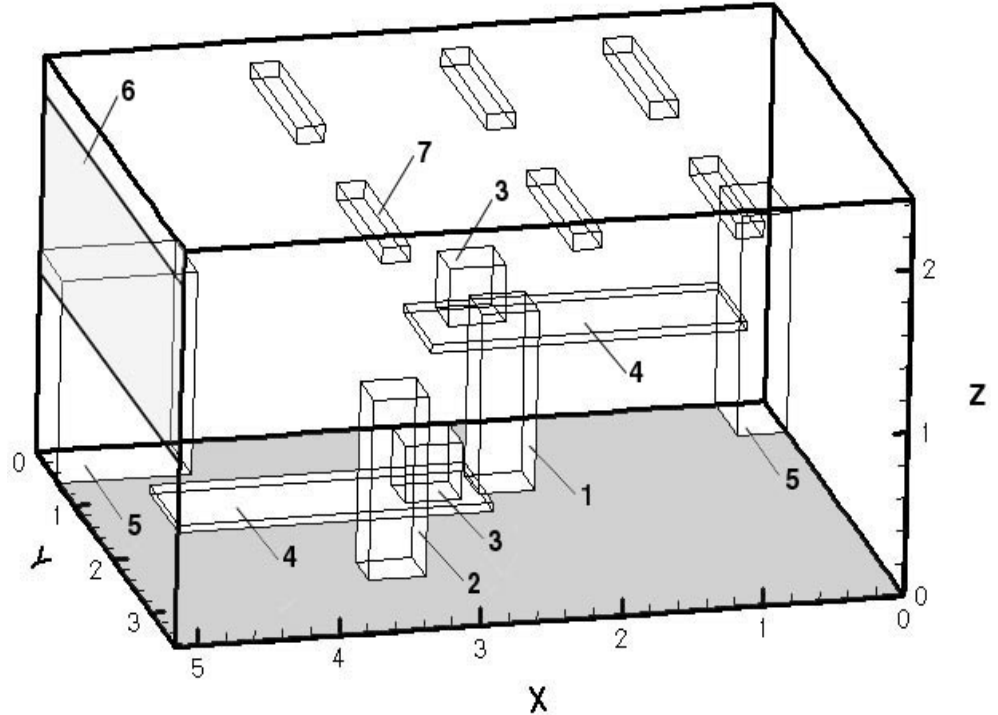

Figure 3 Configuration of the model office. $1=$ occupant $1 ; 2=$ occupant $2 ; 3=$ computers; $4=$ tables; 5 = furniture; 6 = window; 7 = lights. 


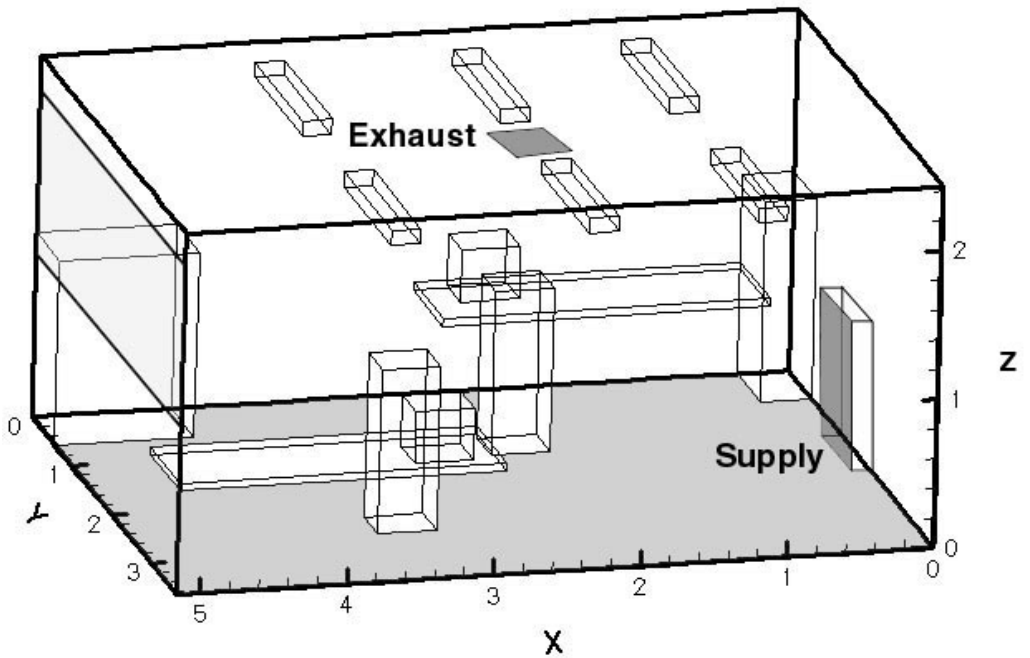

(a)

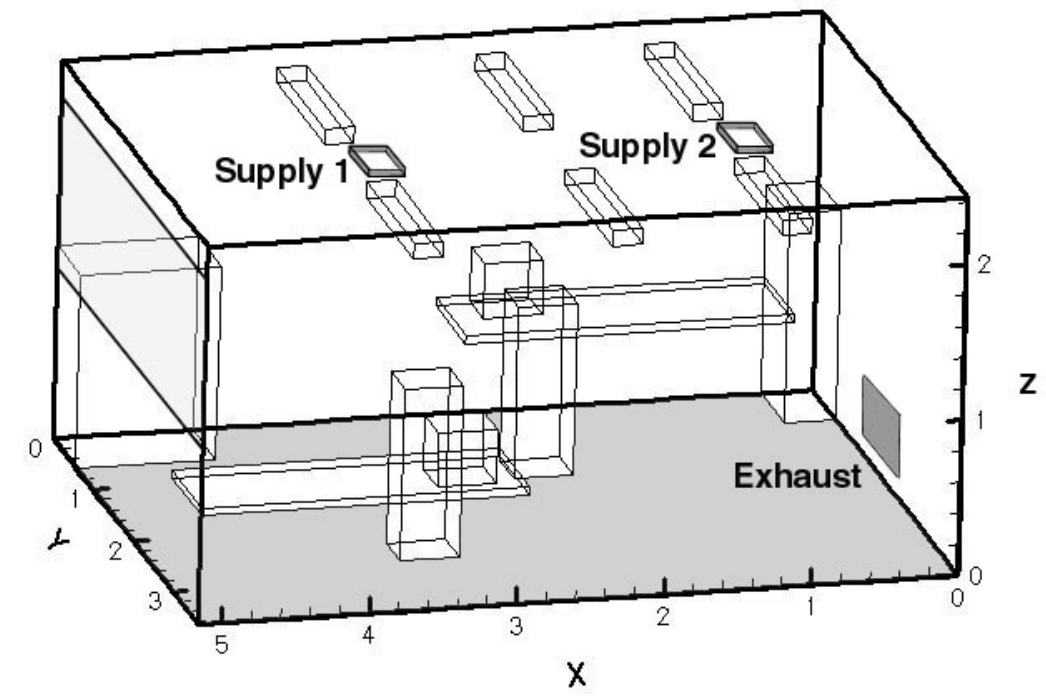

(b)

Figure 4 Schematic of the model office with (a) displacement ventilation, and (b) mixing ventilation. 


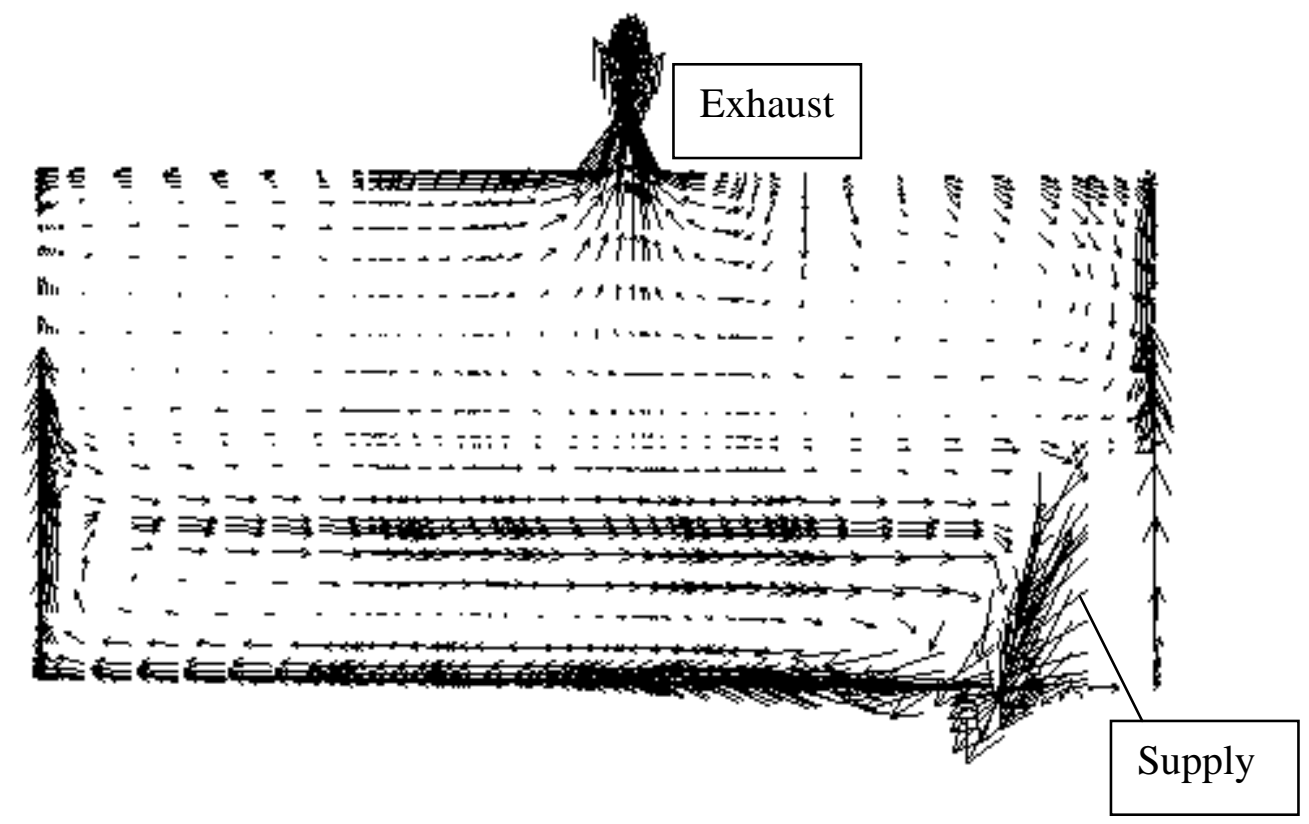

(a)

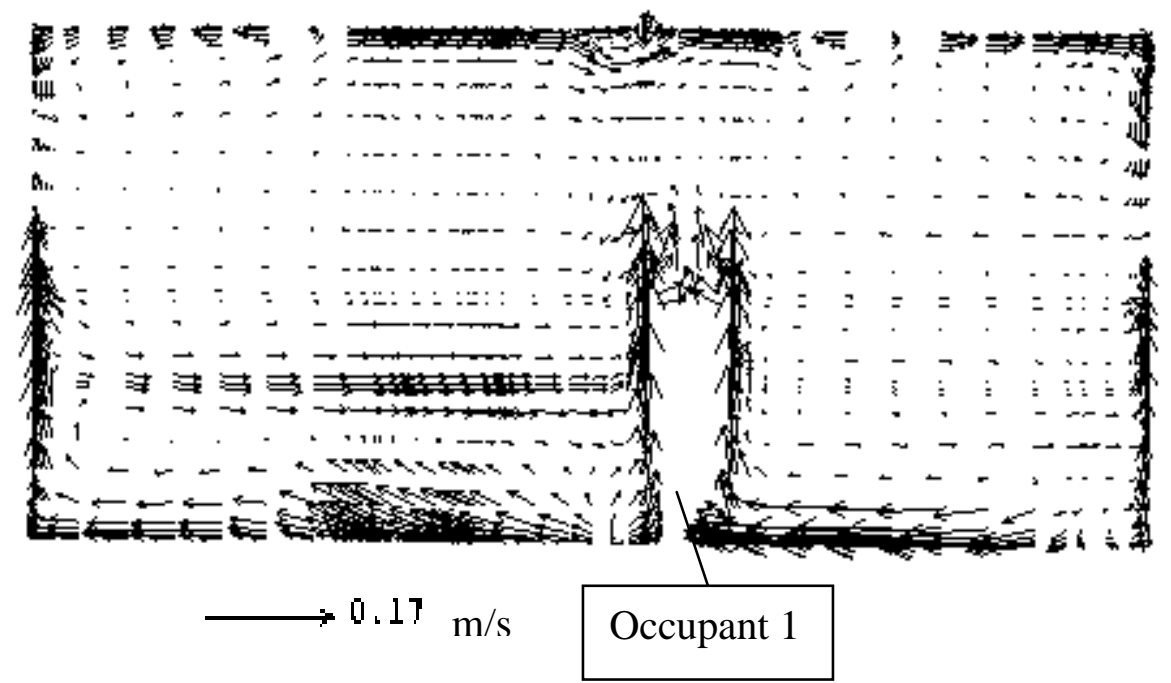

(b)

Figure 5 Predicted velocity vectors for the displacement ventilation: (a) room center $(\mathrm{y}=$ $1.83 \mathrm{~m})$, (b) across occupant $1(\mathrm{y}=1.03 \mathrm{~m})$. 


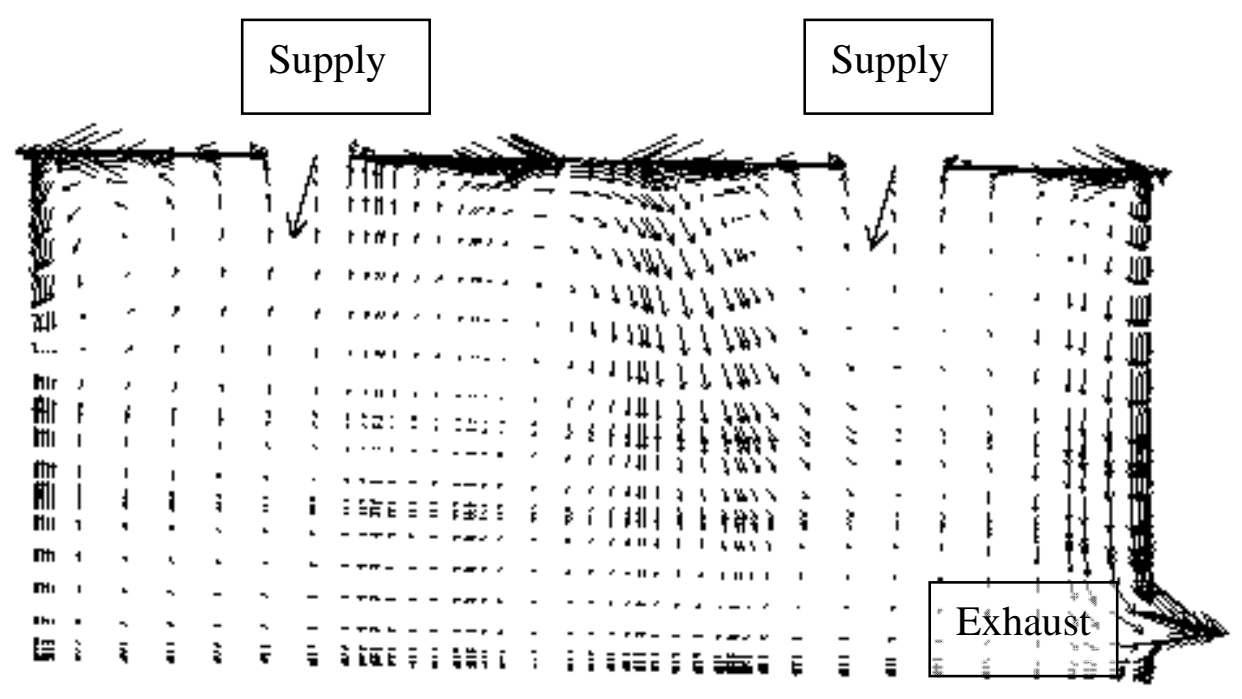

(a)

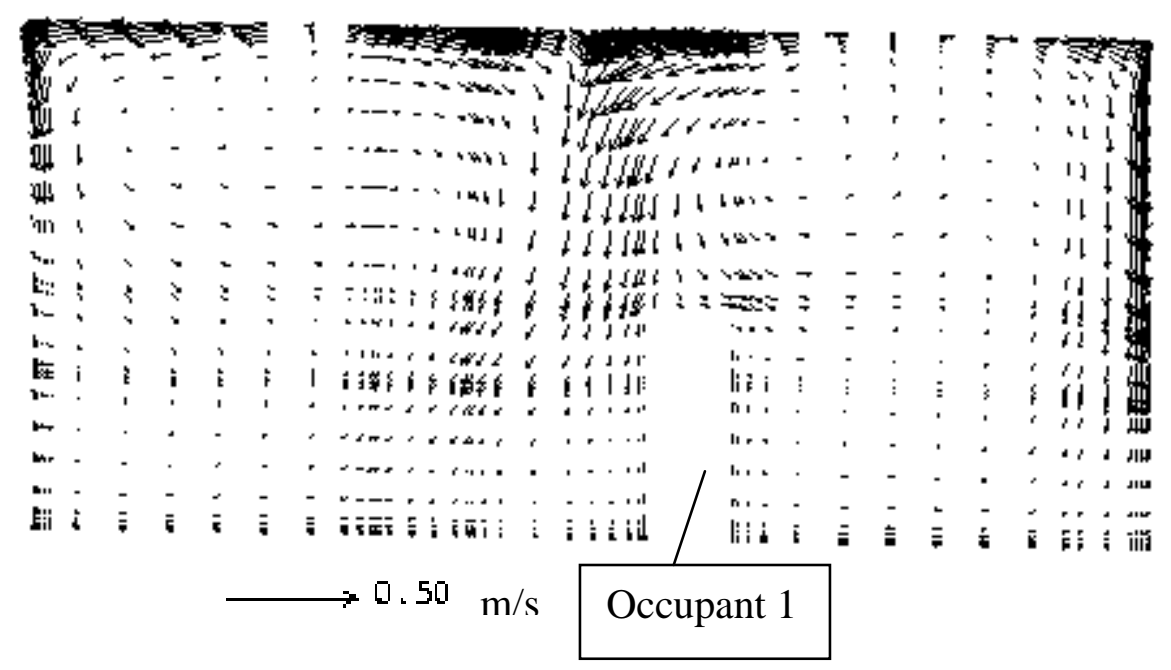

(b)

Figure 6 Predicted velocity vectors for the mixing ventilation: (a) room center $(y=1.83 \mathrm{~m})$, (b) across occupant $1(\mathrm{y}=1.03 \mathrm{~m})$. 


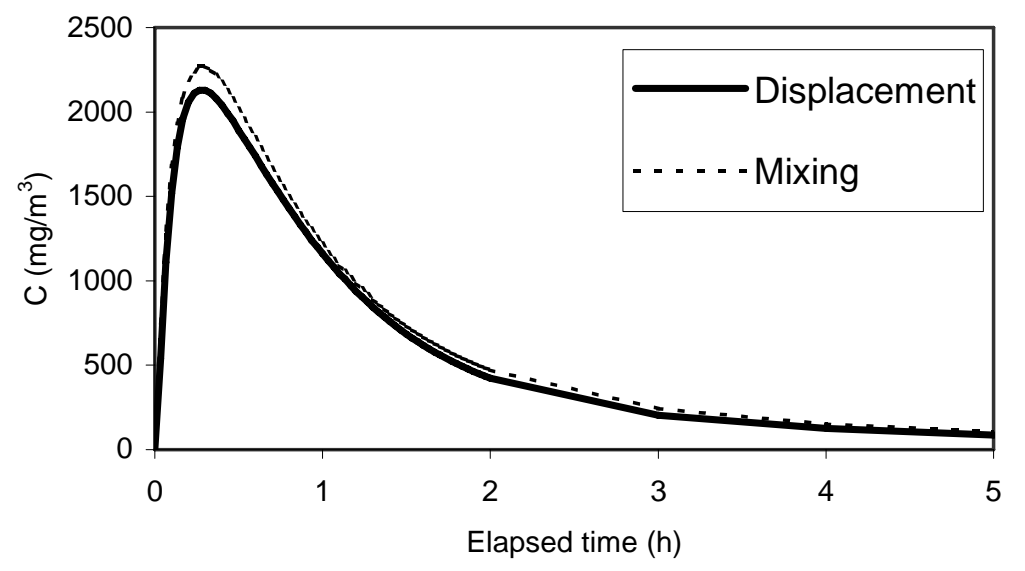

(a)

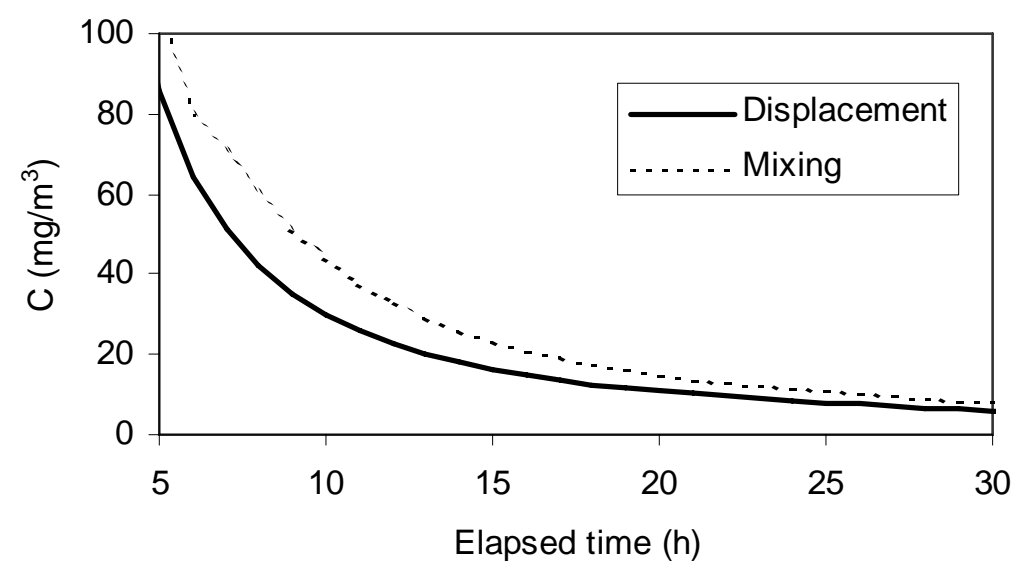

(b)

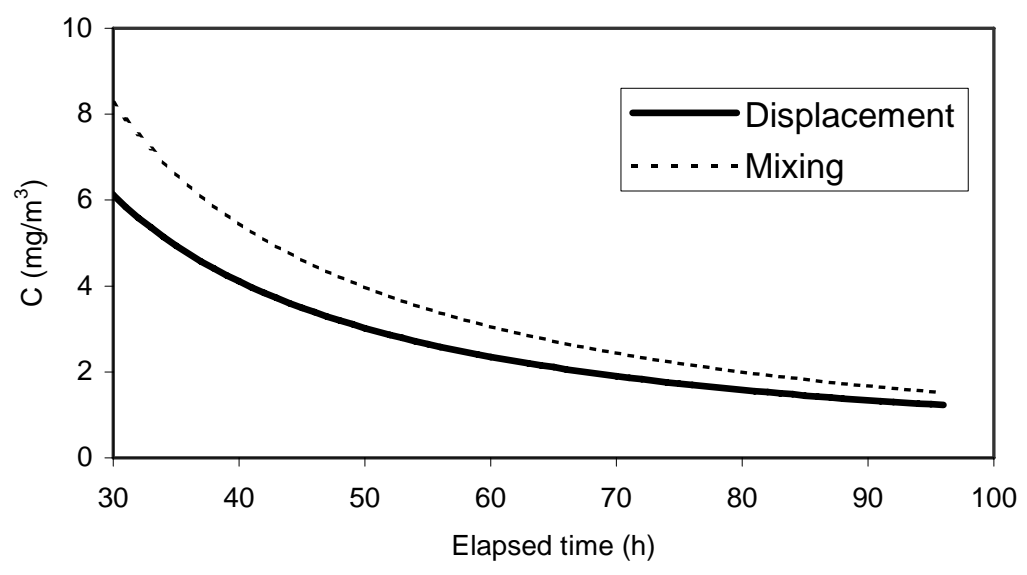

(c)

Figure 7 Predicted VOC concentrations at the breathing level for occupant 1 with the source (freshly painted wood stain) on the floor and sinks (gypsum board) from the vertical walls: (a) 0 $-5 \mathrm{~h}$; (b) 5 - $30 \mathrm{~h}$; (c) $30-96 \mathrm{~h}$. 


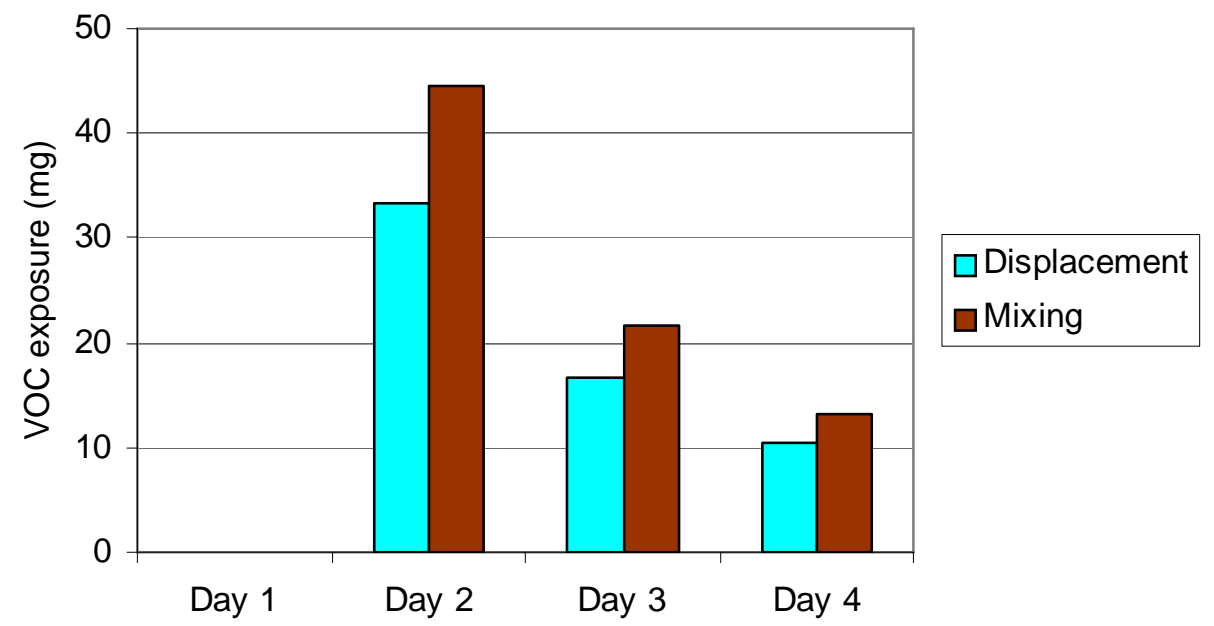

Figure 8 Daily cumulative VOC exposures for occupant 1, assuming the occupant stays 9 am - 7 $\mathrm{pm}$ at the fixed location within the room, starting from the second day. 


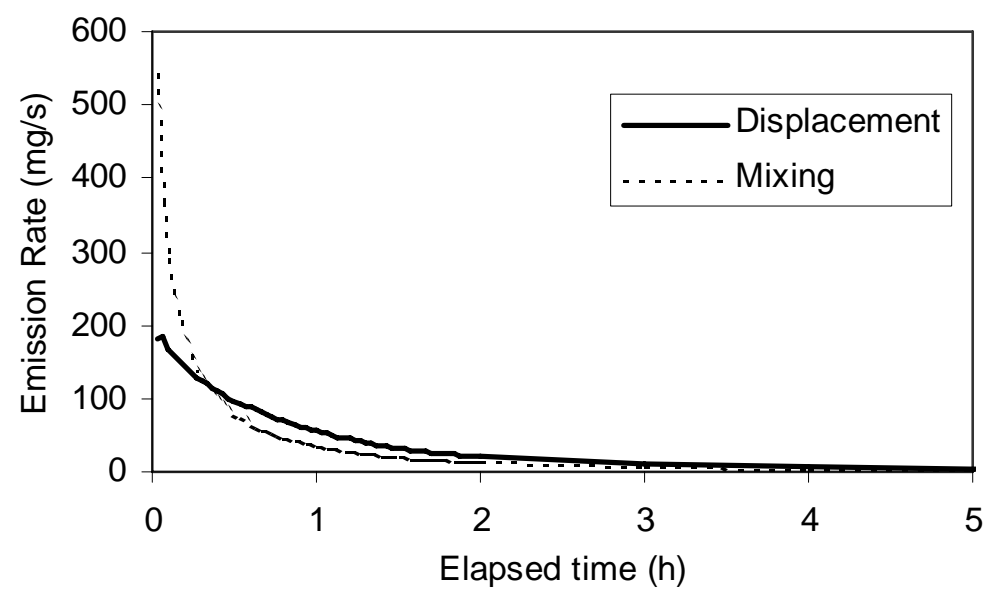

(a)

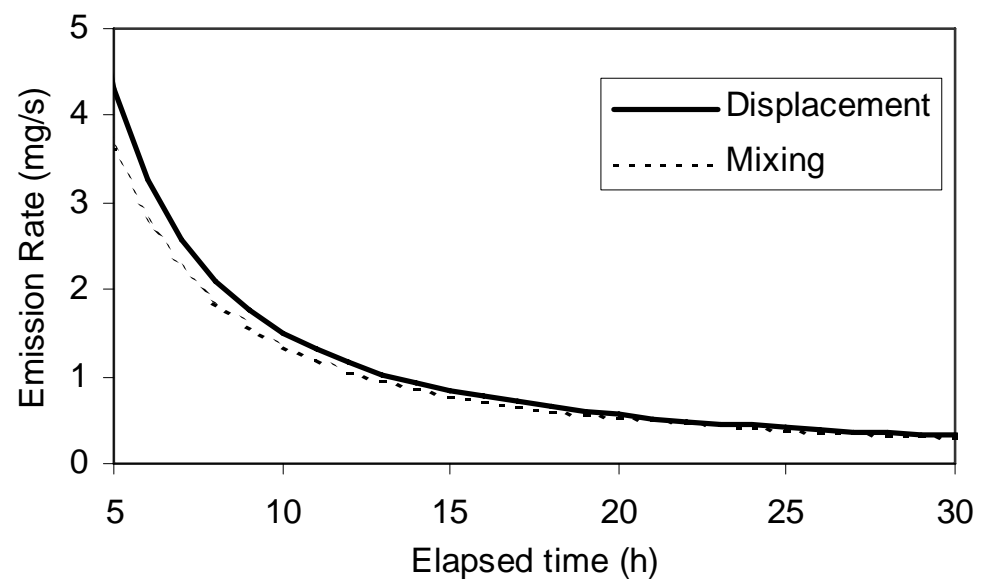

(b)

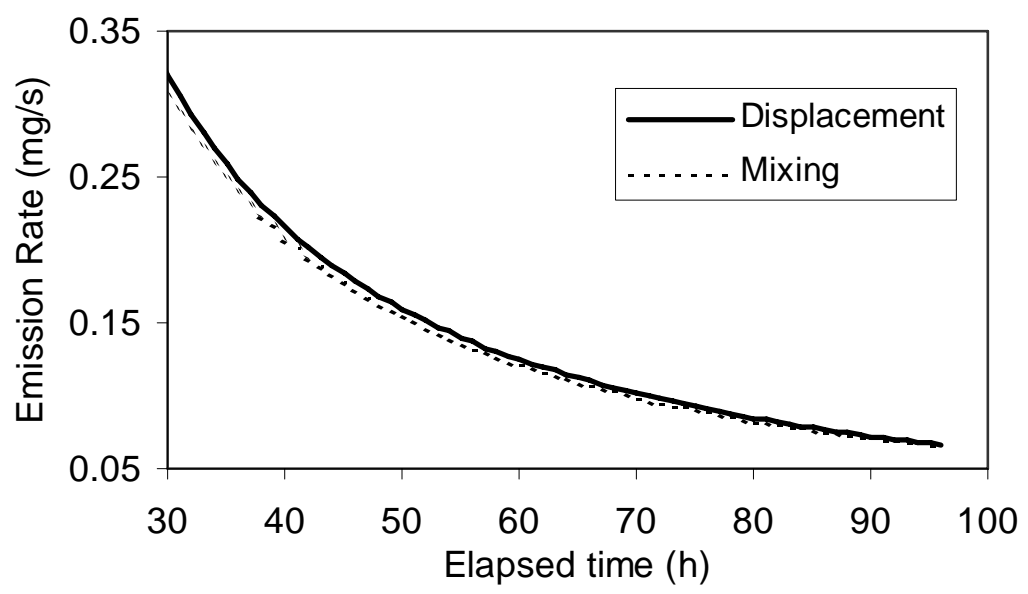

(c)

Figure 9 Predicted TVOC emission rates from the source (freshly painted wood stain) under different ventilation systems: (a) $0-5 \mathrm{~h}$; (b) $5-30 \mathrm{~h}$; (c) $30-96 \mathrm{~h}$. 


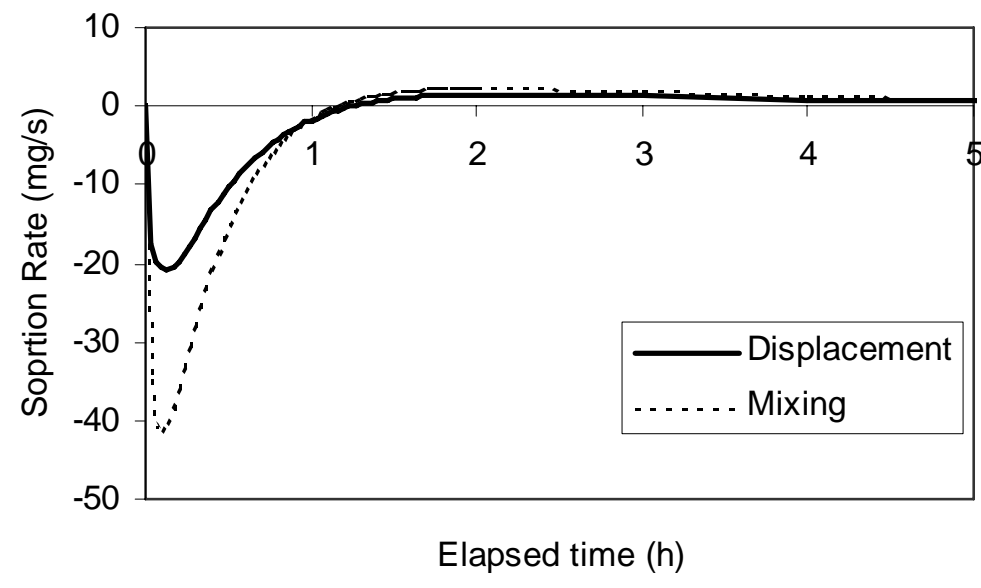

(a)

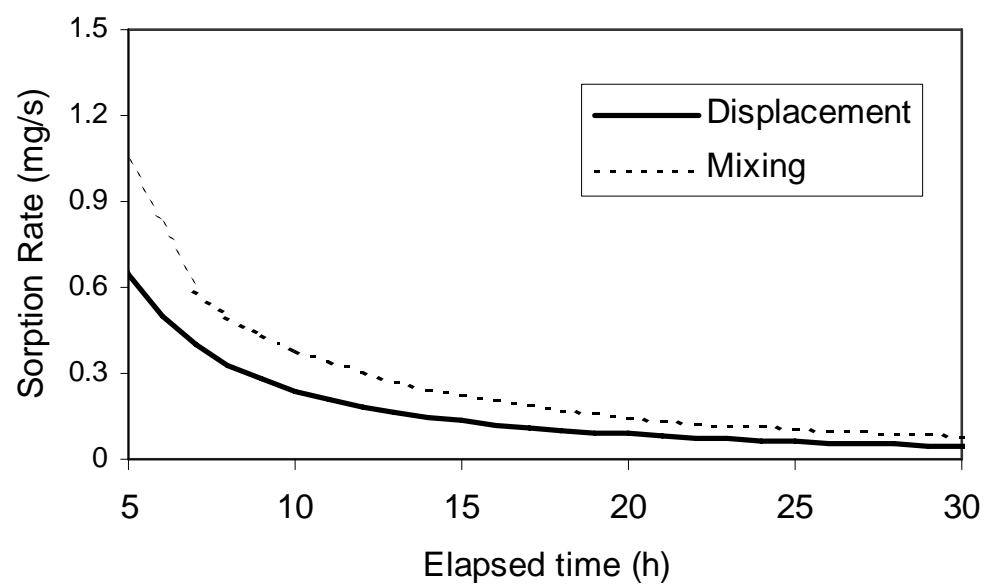

(b)

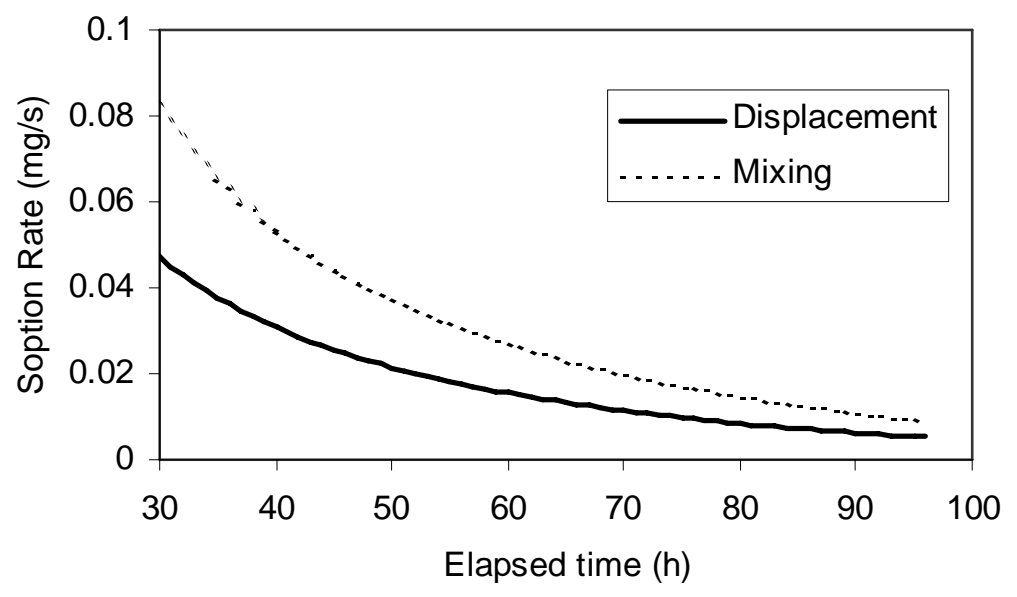

(c)

Figure 10 Predicted VOC sorption rates due to the sinks (unpainted gypsum board) under different ventilation systems: (a) $0-5 \mathrm{~h}$; (b) $5-30 \mathrm{~h}$; (c) $30-96 \mathrm{~h}$. 


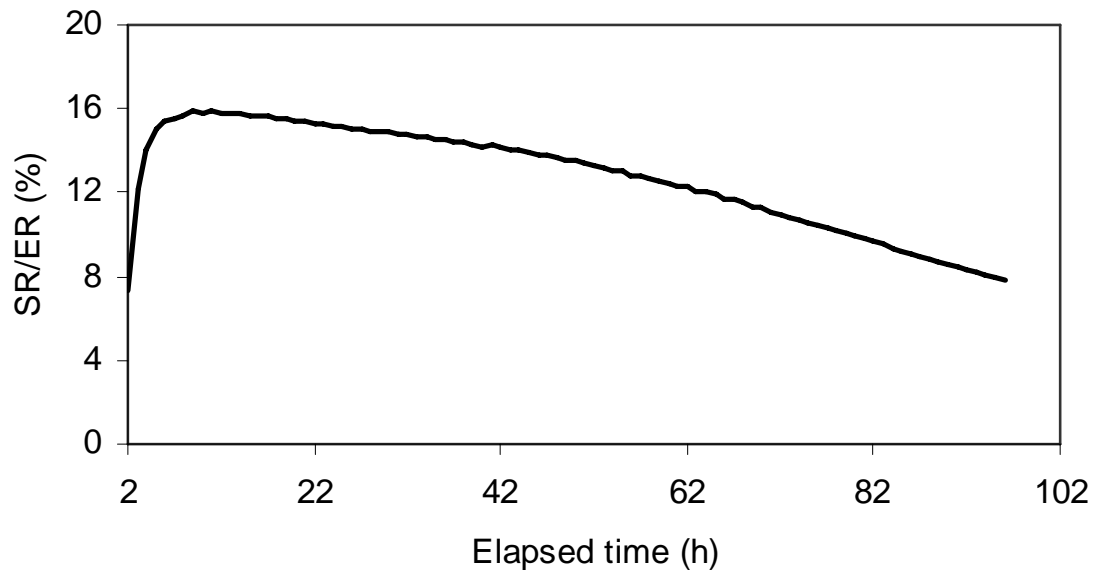

Figure 11 Percentage of desorption rate by the sinks compared to the emission rate from the source at the same time. 